\title{
The Effect of Flowrate and Effectiveness on Theoretical Design and Thermal Characteristic of a GHE
}

\author{
T.M. Yusof ${ }^{1,2 *}, M . F$. Basrawi $^{1}, A$. Shahrani $^{1}, H$. Ibrahim $^{1}$ \\ ${ }^{1}$ Faculty of Mechanical Engineering, Universiti Malaysia Pahang, 26600 Pekan, Pahang, Malaysia. \\ ${ }^{2}$ Automotive Excellent Centre, Universiti Malaysia Pahang, 26600 Pekan, Pahang, Malaysia.
}

\begin{abstract}
Ground heat exchanger is an exciting technique to reduce energy consumption in building especially in hot climate countries. Implementation of GHE for commercial unit in Malaysia is almost none in record. Thus, performance study of the GHE in Malaysia is crucial to be conducted either experimentally or numerically. Therefore, this paper presents the performance of GHE in term of effectiveness, outlet temperature and rate of heat transfer based on mathematical model. The model is developed based on cross flow heat exchanger with one fluid unmixed. There are two variable parameter used in the analysis which is effectiveness and flowrate of the air for 25 meter length of a PVC pipe. Three effectiveness values which is 0.8 , 0.9 and 0.99 have been analysed in this study. Meanwhile, flowrate of air is ranging from 0.02 to $0.2 \mathrm{~kg} / \mathrm{s}$. Results show that flowrate at $0.02 \mathrm{~kg} / \mathrm{s}$ gives great temperature reduction in the pipe compared with higher flowrate. However, flowrate of $0.2 \mathrm{~kg} / \mathrm{s}$ produces higher cooling potential. Characteristic of the GHE for the rate of heat transfer with 80, 90 and 99 percent effectiveness also have been developed and it has been found that effectiveness of 0.9 provide good combination between flowrate and the rate of heat transfer for 25 meter length of the pipe
\end{abstract}

\section{Introduction}

Ground or soil contains natural source of energy which can be used at any time especially for cooling and heating. At certain depth below the surface, its temperature is higher than the ambient air temperature in winter and lower in summer [1]. In addition, the temperature remains almost constant throughout the year. In the most geographical location, the constant ground temperature is equal to the annual mean ambient temperature [2]. Thus, the temperature condition makes the ground itself having significant potential for cooling and heating for all year long. The cooling and heating potential under the ground can be extracted by means of ground heat exchanger (GHE). Application of ground heat exchanger (GHE) is a method to utilize ground temperature either for cooling and heating consequently reduce energy used for space thermal comfort. The GHE has been applied to building thermal comfort [3-5] and agricultural greenhouse [6-9].

\footnotetext{
*Corresponding author: myusof@ump.edu.my
} 
The GHE is a simple heat exchanger which requires a pipe or several pipes buried under the ground. There is no complex equipment needed besides circulating air blower to circulate air throughout the GHE pipe. Performance of the GHE system is a main issue in evaluating GHE's capability and it is subjected to geographical factor and local ground temperature [10]. Derbel and Kanoun [11] reported that the ground temperature will reduce as the depth of the ground increase in the summer. Temperature amplitude throughout the year gets attenuated and constant at the same magnitude of annual mean ambient temperature when the depth of the ground increased $[1,12]$.

The implementation of GHE has been conducted in few countries worldwide such as in India, Germany, Switzerland, Greece and Kuwait. Both experimental and numerical studies have been done for the specific geographical location and climate condition. The early study of a comprehensive numerical model analysis was conducted by Tzaferis et al., which consisting of 6 models of one dimensional (1D) and two models of two-dimensional (2D) algorithms [13]. The design study of GHE has been conducted by [4] based on 1D analytical method. The study focused on influence of design parameters of the heat exchanger on the thermo-hydraulic performance which considering the effectiveness of the heat exchanger based on NTU.

Al-Ajmi et al., [2] was modelled the GHE as a cross flow heat exchanger with one fluid unmixed and another fluid mixed. The effectiveness of the heat exchanger based on NTU has been used and the model has been encoded within TRNSYS. Lee and Strand [14] have developed a heat transfer module based on 1D model and introduced it into EnergyPlus program. Validation has been conducted against previous studies [2, 15]. Ascione et al. [12], have analyzed performance of GHE based on heat transferring process between air inside the tube and the soil. The analysis conducted based on dynamic building energy simulation codes in order to obtain energy requirement for different Italian climate. They have summarized that the GHE is economically acceptable with simple payback of five to nine years. Derbel et al. [16] have conducted theoretical and experimental study of the GHE. A mathematical model for theoretical study has been developed based on circular cross flow heat exchanger with one fluid unmixed. In the study, they have inspired input parameter from Al-Ajmi et al. [2].

In Malaysia, Alam et al. [17] conducted a study on energy efficient using geo cooling system. Ground temperature has been implemented based on China climate Cui et al. [18] with lowest temperature of $19.7^{\circ} \mathrm{C}$ at $10 \mathrm{~m}$ depth. Meanwhile, Sanusi et al. [19] summarized that depth of $1 \mathrm{~m}$ could give best performance of the GHE for Malaysia climate. Temperature variation obtained were only based on two seasons; wet and dry seasons. Towards of GHE implementation in wide application at different geographical region, therefore this paper discusses theoretical design and thermal characteristic of the GHE based on Malaysia climate condition.

\section{Methodology}

The GHE was modelled as an unmixed cross-flow heat exchanger. Thermal interaction from the air inside the pipe to the ground surrounding in cylindrical form occurred by means of convection and conduction. These two modes of heat transfer have been implemented in developing the mathematical model of the GHE as discussed by $[3,4,8,10]$. The convection heat transfer will take place first from the air to the inner surface of the pipe. Then, it will followed by conduction heat transfer from the inner surface of the pipe to the ground surrounding. Figure 1 shows the model of GHE as an unmixed cross-flow heat exchanger and mode of heat transfer in the pipe to the ground surrounding. Air with inlet temperature of $T_{\text {air }}$ entering the pipe and leave the pipe at $T_{\text {out }}$. At any distance ' $y$ ' along the pipe, the air 
temperature is $T_{a(y)}$ and $\Delta T$ is the temperature different between air inside the pipe $\left(T_{a(y)}\right)$ and constant ground temperature of $T_{x, y}$.

Therefore, the rate of heat transfer received by the ground in the differential section of $d y$ for arbitrary length is expressed by Eq. (1);

$$
d \dot{Q}=U \pi D\left[T_{a(y)}-T_{z, t}\right] d y
$$

On the other side of heat transfer in which the rate of heat been transferred by the air inside the pipe in the differential section of $d y$ is shown by Eq. (2):

$$
d \dot{Q}=-\dot{m}_{a i r} c_{p}\left[d T_{a(y)}\right]
$$

Solve Eq.(1) and Eq.(2) yields the outlet temperature at the end of the pipe yields Eq.(3).

$$
T_{\text {out }}=T_{z, t}+\left(T_{\text {air }}-T_{z, t}\right) e^{-U A / \dot{m}_{\text {air }} c_{p}}
$$

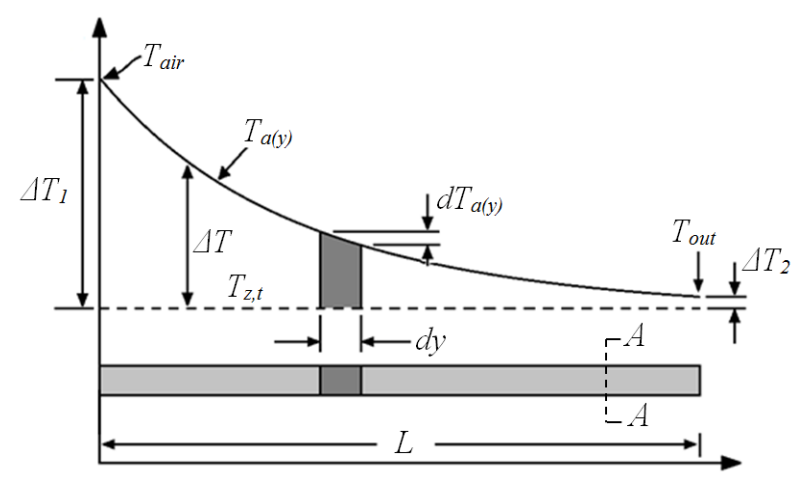

(a)

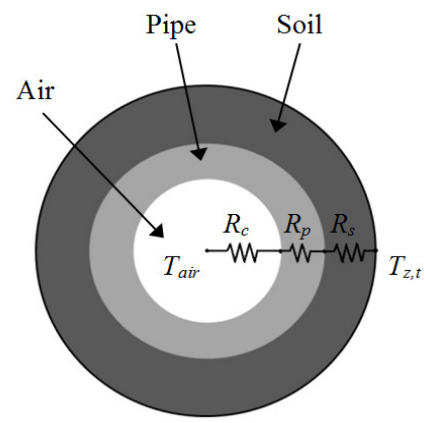

(b)

Fig. 1. (a) Schematic of unmixed cross-flow heat exchanger in GHE pipe, and (b) Section A - A of the GHE pipe for thermal model.

Eq.(3) can be rewritten as Eq.(4), which is;

$$
\frac{T_{\text {out }}-T_{\text {air }}}{T_{z, t}-T_{\text {air }}}=1-e^{-U A / \dot{m}_{\text {air }} c_{p}}
$$

Eq. (4) is describing effectiveness of the ground heat exchanger which future can be written as;

$$
\varepsilon=1-e^{-U A / \dot{m}_{\text {air }} c_{p}}
$$

And Eq.(5) can be simplified as shown by Eq.(6).

$$
\varepsilon=1-e^{-N T U}
$$

Theoretical design of the GHE can be referred to equation 6 for the certain effectiveness. There are three effectiveness will be investigated which is $0.8,0.9$ and 0.99 . Therefore suitable length of the GHE for the three effectiveness are obtained based on eq. (7) to eq.(9). 


$$
\begin{aligned}
& L \approx \frac{1.75 \dot{m}_{a i r} c_{p}}{U \pi D} \\
& L \approx \frac{2.5 \dot{m}_{a i r} c_{p}}{U \pi D} \\
& L \approx \frac{5 \dot{m}_{a i r} c_{p}}{U \pi D}
\end{aligned}
$$

Constant used in Eq.(7) and Eq.(9) were based on [4] and [10]. Meanwhile, constant 2.5 in Eq.(8) used by the author for effectiveness 0.9 in the present work.

The analysis was conducted with flowrate of 0.02 to $0.2 \mathrm{~kg} / \mathrm{s}$, air inlet temperature $\left(T_{\text {air }}\right)$ of $35^{\circ} \mathrm{C}$ and $100 \mathrm{~mm}$ size of PVC pipe class D according to MS 628 Standard. Ground temperature is taken at minimum temperature of the depth of 2 metre below the ground surface [20-22]. Table 1 tabulates characteristic and condition of the pipe used in the study.

Table 1. Parameter of GHE pipe and its surrounding.

\begin{tabular}{|l|l|}
\hline \multicolumn{1}{|c|}{ Parameters } & \multicolumn{1}{c|}{ Value } \\
\hline $\begin{array}{l}\text { GHE of PVC pipe } \\
\text { Standard outside diameter }\end{array}$ & $\begin{array}{l}\text { Min: } 114.1 \mathrm{~mm} \\
\text { Max: } 114.5 \mathrm{~mm} \\
\text { Min: } 6.0 \mathrm{~mm} \\
\text { Mall thickness }\end{array}$ \\
$\begin{array}{l}\text { Length } \\
\text { Thermal conductivity }\end{array}$ & $0.18 \mathrm{~mm}$ \\
\hline Thermal conductivity of soil & $0.655 \mathrm{~W} / \mathrm{K} \cdot \mathrm{K}$ \\
\hline Mass flowrate & $0.02-0.2 \mathrm{~kg} / \mathrm{s}$ \\
\hline Air inlet temperature & $35^{\circ} \mathrm{C}$ \\
\hline $\begin{array}{l}\text { Ground temperature (taken as } \\
\text { minimum temperature at } 2 \mathrm{~m} \\
\text { depth) }\end{array}$ & $24.54{ }^{\circ} \mathrm{C}$ \\
\hline
\end{tabular}

\section{Results and Discussions}

\subsection{Effectiveness and NTU}

Effectiveness is a measure of heat exchanger performance and it has been defined as a function of number of transfer unit (NTU). Figure 2 shows effectiveness $(\varepsilon)$ versus NTU for inlet temperature $\left(T_{\text {air }}\right)=35^{\circ} \mathrm{C}$, mass flowrate $(\dot{m})$ of $0.02,0.11$ and $0.2 \mathrm{~kg} / \mathrm{s}$ and outside diameter $(O D)=100 \mathrm{~mm}$. Pattern of the graph is similar as in other heat transfer reference books under heat exchanger's chapter. This graph also shows close agreement with Paepe and Janssens [4]. There is no different in term of graph patent for $\varepsilon-\mathrm{NTU}$ with different flowrate and pipe size as shown by the figure.

The effectiveness also can be shown as a function of pipe length $(L)$ as depicted by Figure 3 . The effectiveness increase rapidly within the first $2 / 3$ of the pipe length and there is small increment in effectiveness in the final $1 / 3$ of the pipe. The pattern of the graph will differ for each different flowrate in which the effectiveness line will move to the left hand side for the flowrate less than $0.11 \mathrm{~kg} / \mathrm{s}$ and wise versa as shown by Figure 3. For the flowrate of $0.02-$ 
$0.2 \mathrm{~kg} / \mathrm{s}$, the length the required length of the pipe is ranging from 3.2 to 17.2 metre to obtain effectiveness of 0.9 .

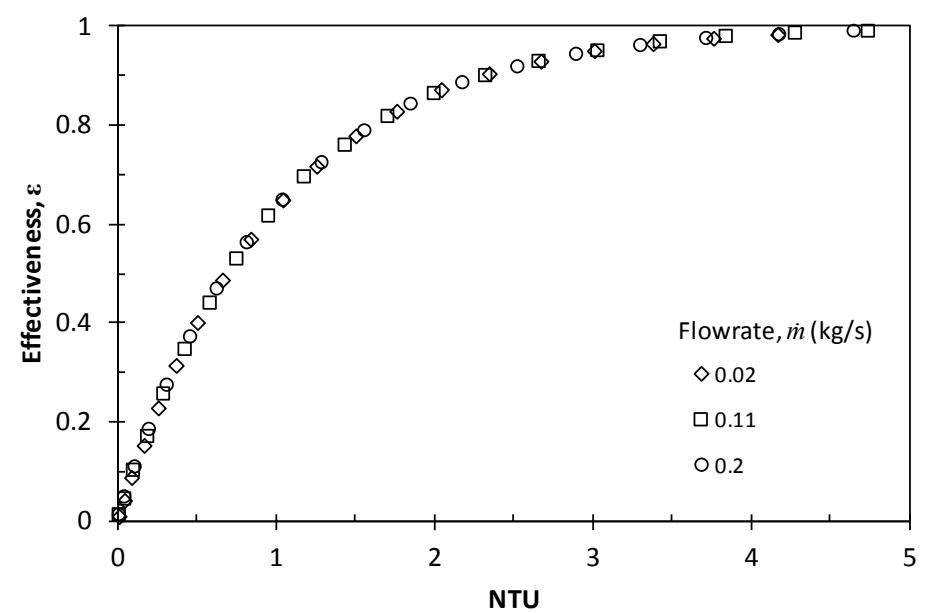

Fig. 2. $\varepsilon$ as a function of NTU for $\dot{m}=0.02,0.11$ and $0.2 \mathrm{~kg} / \mathrm{s}$.

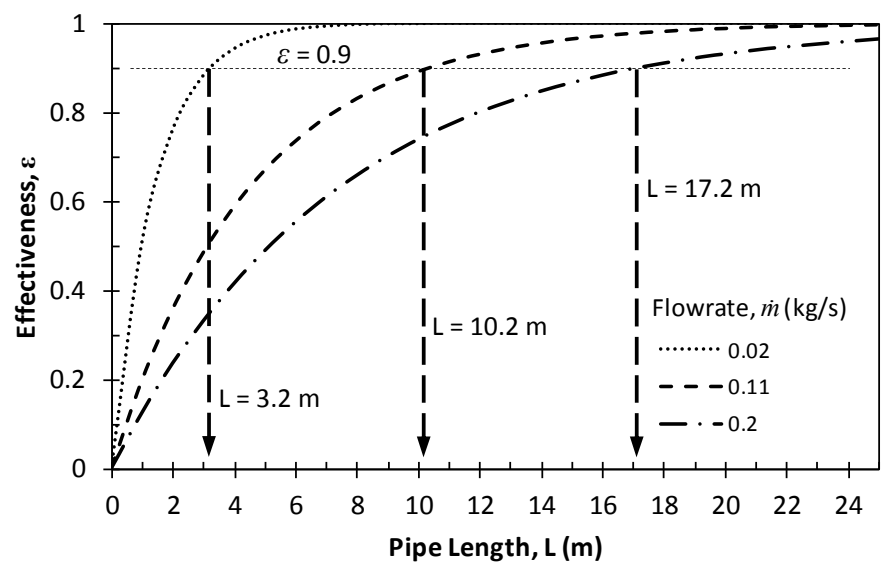

Fig. 3. $\varepsilon$ as a function of $L$ for different flowrate.

\section{2 $\mathrm{T}_{\text {out }}$ as an Effect of Mass Flowrate}

There are seven different flowrate of air used in this study which ranging from $0.02 \mathrm{~kg} / \mathrm{s}$ to $0.2 \mathrm{~kg} / \mathrm{s}$. The flowrate give significant effect to the air temperature reduction in the GHE. Temperature reduction occurred rapidly in short length of pipe at low flowrate of air which is for $0.02 \mathrm{~kg} / \mathrm{s}$ compared with the other flowrate as shown in Figure 4. Therefore, air temperature inside the GHE pipe with $\dot{m}=0.02 \mathrm{~kg} / \mathrm{s}$ gets constant earlier than the other flowrate. In this analysis, it has been found that the increasing of flowrate of the air in the GHE pipe will increasing the length of the GHE pipe to get design temperature of air inside the GHE pipe. Besides that, the outlet temperatures of air at certain effectiveness are directly related to the length of pipe as shown in Figure 3. 


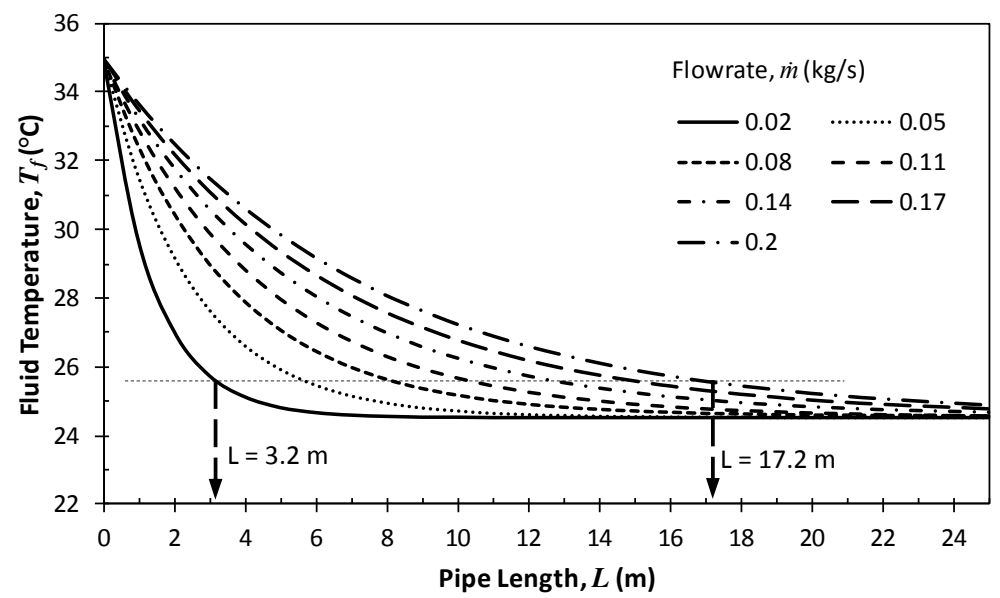

Fig. 4. $T_{\text {out }}$ as a function of $L$ for different flowrate.

\section{3 $Q$ as an Effect of Mass Flowrate at Different $\varepsilon$}

The rate of heat transfer $(Q)$ has been plotted as a function of length with different flowrate. The rate of heat transfer will increase as a function of length and mass flowrate. Design line of the GHE at $\varepsilon=0.8, \varepsilon=0.9$ and $\varepsilon=0.99$ have been plotted together with the $Q$ become the significant characteristic of the GHE as shown by Figure 5. Therefore, design boarder can be determined for each effectiveness line.

The effectiveness of the GHE will increase by increasing the rate of heat transfer which is to the right hand side of the line $\varepsilon=0.9$. Reduction of effectiveness than 0.9 to the left hand side means the rate of heat transfer will decrease. However, requirement of cooling should be obtained before using the figure as reference in designing GHE

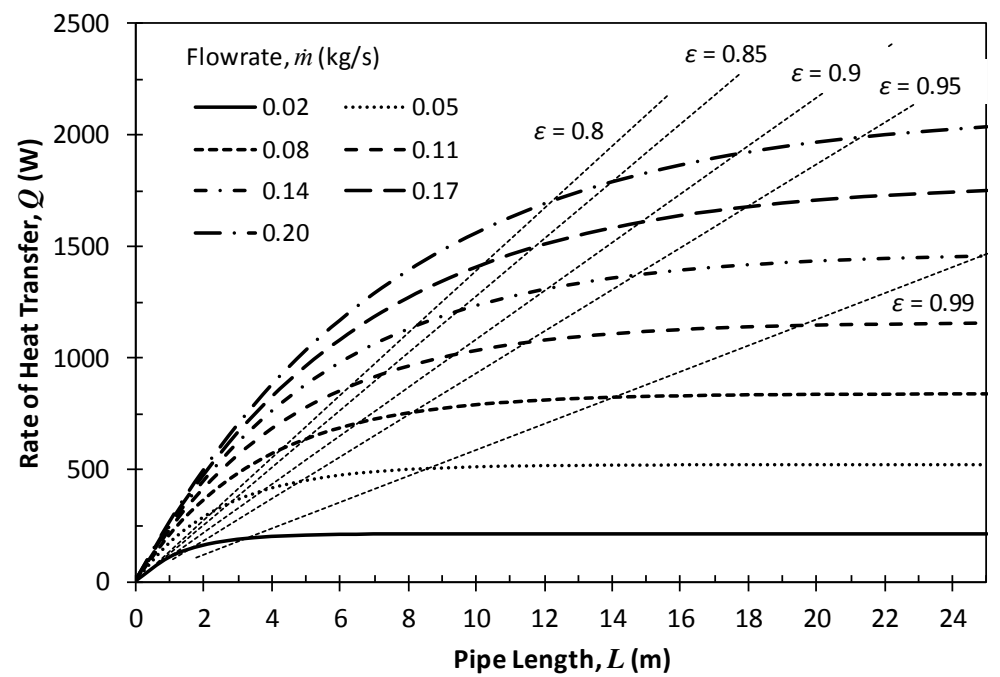

Fig. 5. Design characteristic of GHE with specific effectiveness. 


\section{Conclusion}

Performance characteristic of the GHE based on theoretical study has been developed with different flowrate at air inlet temperature of $35^{\circ} \mathrm{C}$, pipe size of $100 \mathrm{~mm}$ and $25 \mathrm{~m}$ length. Plot of effectiveness and NTU as a function of pipe length have been established. For design effectiveness of GHE at 0.9, the appropriate length of pipe is ranging from 3.2-17.2 meter with the flowrate is ranging from 0.02 to $0.2 \mathrm{~kg} / \mathrm{s}$. Outlet temperatures of air also have direct relationship to the effectiveness of the GHE for the range of the study. Design chart of the rate of heat transfer also have been developed for the flowrate of 0.02 to $0.2 \mathrm{~kg} / \mathrm{s}$ with effectiveness line of $0.8,0.9$ and 0.99 . The appropriate length can be obtained for required rate of heat transfer and it can be used as reference chart in designing GHE.

The authors would like thanks to the Faculty of Mechanical Engineering for providing the research facilities and Universiti Malaysia Pahang (www.ump.edu.my) for financial support.

\section{References}

1. T. T. Chow, H. Long, H. Y. Mok, and K. W. Li, Energy Build. 43(12), pp. 3568-3575 (2011).

2. F. Al-Ajmi, D. L. Loveday, and V. I. Hanby, Build. Environ. 41(3), pp. 235-244 (2006).

3. M. S. Sodha, A. K. Sharma, S. P. Singh, N. K. Bansal, and A. Kumar, Build. Environ. 20(2), pp. 115-122 (1985).

4. M. De Paepe and A. Janssens, Energy Build. 35(4), pp. 389-397 (2003).

5. T. S. Bisoniya, A. Kumar, and P. Baredar, Renew. Sustain. Energy Rev. 19, pp. 238246 (2013).

6. M. Santamouris, A. Argiriou, and M. Vallindras, Sol. Energy 52(5), pp. 371-378 (1994).

7. M. Santamouris, G. Mihalakakou, C. A. Balaras, A. Argiriou, D. Asimakopoulos, and M. Vallindras, Sol. Energy 55(2), pp. 111-124 (1995).

8. M. K. Ghosal and G. N. Tiwari, Energy Convers. Manag. 47(13-14), pp. 1779-1798 (2006).

9. G. Sharan and R. Jadhav, J. Agric. Eng. 40(1), pp. 1-8 (2003).

10. G. Florides and S. Kalogirou, Renew. Energy 32(15), pp. 2461-2478 (2007).

11. H. B. J. Derbel and O. Kanoun, Appl. Therm. Eng. 30(10), pp. 1091-1100 (2010).

12. F. Ascione, L. Bellia, and F. Minichiello, Renew. Energy 36(8), pp. 2177-2188 (2011).

13. A. Tzaferis, D. Liparakis, M. Santamouris, and A. Argiriou, Energy Build. 18(1), pp. 35-43 (1992).

14. K. H. Lee and R. K. Strand, Energy Build. 40(4), pp. 486-494 (2008).

15. D. Y. Goswami and A. S. Dhaliwal, J. Sol. Energy Eng. 107(2), pp. 141-145 (1985).

16. H. B. J. Derbel, I. Kessentini, and O. Konoun, 5th IEEE International MultiConference on System, Signals and Devices pp. 1-5 (2008).

17. M. R. Alam, M. F. M. Zain, and A. Kaish, Int. J. Sustain. Constr. Eng. Technol. 3(2), pp. 96-105 (2012).

18. Cui W, Liao Q, Chang G, Chen G, Peng Q, and Jen TC, ASME 2011 International Mechanical Engineering Congress and Exposition (IMECE2011) pp. 671-676 (The American Society of Mechanical Engineers, 2011).

19. A. N. Z. Sanusi, L. Shao, and N. Ibrahim, Renew. Energy 49(0), pp. 193-196 (2013).

20. T. M. Yusof, S. Anuar, and H. Ibrahim, Appl. Mech. Mater. 554, pp. 301-306 (2014).

21. T. M. Yusof, S. Anuar, and H. Ibrahim, Int. J. Automot. Mech. Eng. 10, pp. 10 
(2014).

22. T. M. Yusof, S. Anuar, and H. I. Ibrahim, J. Mech. Eng. Sci. 8, pp. 1426-1439 (2015). 